\title{
Establishment of primary cell lines from tissues of the red-eared slider
}

\section{Maria Kulak' ${ }^{1}$, Svetlana Galkina², Alsu Saifitdinova ${ }^{3}$, and Elena Gaginskaya ${ }^{4}$}

${ }^{1}$ Chromas Research Resource Center of Saint Petersburg State University Research Park, Oranienbaumskoye Shosse, 2, Stary Peterhof, Saint Petersburg, 198504, Russian Federation 2Department of Genetics and Biotechnology, Saint Petersburg State University, Universitetskaya nab., 7-9, Saint Petersburg, 199034, Russian Federation ${ }^{3}$ Department of Human and Animal Anatomy and Physiology, Herzen State Pedagogical University of Russia, Moyka nab., 48, Saint Petersburg, 191186, Russian Federation ${ }^{4}$ Department of Cytology and Histology, Saint Petersburg State University, Universitetskaya nab., 7-9, Saint Petersburg, 199034, Russian Federation

Address correspondence and requests for materials to Elena Gaginskaya, elena.gaginskaya@spbu.ru

\begin{abstract}
Primary cell lines of the red-eared slider were established from somatic slider tissues cultivated in appropriate medium for a certain period. Exponential cell growth started after 2 weeks of continuous cultivating. The cells were of various morphology resembling keratinocytes, fibroblasts, and melanocytes, some of them gathered to form dense conglomerates similar to so-called "embryoid bodies". The cell lines were maintained for 3-7 passages before being taken for cytogenetic manipulations. Red-eared slider cell lines derived in this way can be cryopreserved and successfully recovered to provide a source of fixed cells for 3D imaging as well as a source of chromosomes and chromatin fiber preparations for cytological and cytogenetic studies. The protocol for red-eared slider cells was developed on the basis of the experiments described.
\end{abstract}

Keywords: Trachemys scripta elegans, turtles, primary culture, explant.

\section{Introduction}

2019. Establishment of primary cell lines

from tissues of the red-eared slider

Bio. Comm. 64(4): 229-234. https://doi.

org/10.21638/spbu03.2019.401

Author's information: Maria Kulak, Leading Specialist, orcid.org/0000-0002-

1204-4524; Svetlana Galkina, PhD, Associate Professor, orcid.org/0000-0002-7034-

2466; Alsu Saifitdinova, PhD, Associate

Professor, orcid.org/0000-0002-1221-479X;

Elena Gaginskaya, Dr. of Sci. in Biology,

Professor, orcid.org/0000-0003-4967-9053

Manuscript Editor: Anna Malashicheva,

Almazov Federal Medical Research Centre,

Saint Petersburg, Russia

Received: September 13, 2019;

Revised: November 24, 2019;

Accepted: December 2, 2019;

Copyright: ( 2019 Gaginskaya et al.

This is an open-access article distributed

under the terms of the License Agreement

with Saint Petersburg State University,

which permits to the authors unrestricted

distribution, and self-archiving free of

charge.

Funding: The research was sponsored by the Russian Foundation for Basic

Research (project \#18-04-01276A) and

Saint Petersburg State University's

Programme 4 (project \#1.40.1625.2017).

Competing interests: The authors have

declared that no competing interests exist.
The red-eared slider (Trachemys scripta elegans Wied-Neuwied, 1839, Emydidae, Testudines) (Fig. 1) is the most popular pet turtle. Due to its availability, this species serves as a biological model to study temperature-dependent sex determination (Ramsey and Crews, 2007, 2009; Czerwinski et al. 2016), hypertranscriptional type oogenesis diversity, the diversity and evolutionary trends of rRNA gene amplification mechanisms in animals (Koshel et al. 2016), etc. Native to the southern United States and northern Mexico, the red-eared slider has become an invasive species in many areas, and therefore also serves as a model object for the study of salinity adaptation and hypoxia tolerance (Bansal, Biggar, Krivoruchko, and Storey, 2016; Hong et al. 2019).

There is no information of any stable cell lines in cell banks for T.scripta. For reptilia, commercial cell lines are in general limited to one chelonian cell line TH-1 from the terrestrial turtle Terrapene carolina (https://www.lgcstandardsatcc.org/products/all/CCL-50.aspx). However, the literature indicates that primary somatic cell lines have been established and reported for several Testudines species, such as the Galapagos giant tortoise Geochelone nigra (Goldstein, 1974), green turtle Chelonia mydas (Mansell, Jacobson, and Gaskin, 1989; Lu et al., 1999), snapping turtle Chelydra serpentina, painted turtle Chrysemys picta, mud turtle Kinosternon flavescens (Christiansen et al., 2001), hawksbill sea turtle Eretmochelys imbricata (Fukuda et al., 2012), olive ridley sea turtle Lepidochelys olivacea (Fukuda et al. 2014), loggerhead sea turtle Caretta caretta (Webb et al., 


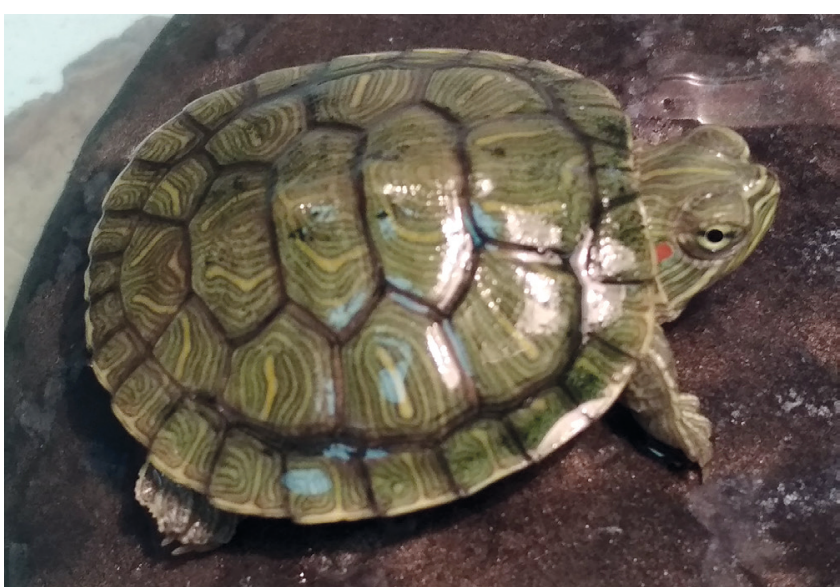

Fig. 1. Juvenile red-eared slider Trachemys scripta elegans.

2014; Fukuda et al., 2018), and Chinese soft-shelled turtle Pelodiscus sinensis (Guo et al., 2016). Establishment of an ovarian stem-like cell line from the P. sinensis was recently described (Xu et al., 2018). A common conclusion is that reptile cells require a cultivation temperature of $28-30^{\circ} \mathrm{C}$ and a high concentration of antibiotics and antimycotics at the beginning of cultivation. Available data indicate that telomerase is often present in adult somatic reptile tissues, and telomere-based replicating aging is unlikely to occur in most species studied to date (Gomes, Shay and Wright, 2010). Telomerase activity was also detected in old painted turtles (Chrysemys picta), and cultured cells from this species were still successfully dividing at passage 120 (Paitz et al. 2004).

Here we describe a procedure optimized to establish primary cultures of fibroblast-like cells from the red-eared slider somatic tissues using both enzymatic and migration methods. Maintained cell cultures can facilitate the study of viruses and provide a source of chromosomes, chromatin fibers, interphase nuclei, DNA, RNA and fixed cells preparations that can be used in molecular, cytogenetic, immunocytochemical and 3D cytological studies. Primary cell cultures from the redeared slider might represent a good model system for the analysis of telomerase activity. Established cell lines can be cryopreserved for longtime storage.

\section{Animals:}

Red eared sliders can be purchased from authorized zoo traders or by agreement with zoos. They can be maintained in captivity according to common recommendations for freshwater turtle care (Mahlin, 1997; https:// www.thesprucepets.com/red-eared-sliders-1238387 http://www.reptilesmagazine.com/Red-Eared-SliderCare-Sheet/). The female red-eared turtle used here was maintained in a small closed population at the Laboratory of Chromosome Structure and Function. Handling and euthanasia followed protocols approved by the Saint Petersburg State University Ethics Committee (Statement \#131-03-2).

\section{Equipment:}

- Laminar flow hood (recirculating/top-vented);

- Humidified carbon dioxide incubator (adjusted to $28^{\circ} \mathrm{C}, 5 \% \mathrm{CO}_{2}$ );

- Cytological centrifuge with a batch rotor;

- Inverted microscope equipped with phase-contrast objectives and rings (e.g. Leica, Zeiss, Olympus, Nikon);

- Water bath or an air incubator for warming up cell culture medium and working solutions;

- Fridge and $-20^{\circ} \mathrm{C}$ freezer;

- Magnetic stirrer.

\section{Instruments:}

- Desiccator;

- Sterile stainless-steel ophthalmic scissors;

- Sterile scalpel blades and sterile histological needles;

- Sterile histological forceps;

- Sterile $5 \mathrm{ml}$ syringes without needles;

- Sterile glass weighing bottles with a ground cover or small sterile glasses with a foil cover;

- Sterile stir bars;

- Sterile slides cut into $\sim 20 \times 20 \mathrm{~mm}$ pieces;

- Tissue culture flasks typically of $25 \mathrm{~cm}^{2}$ (e.g. Corning Falcon \#363108) or $75 \mathrm{~cm}^{2}$ (e.g. SPL Life Sciences \#70075);

- Cell culture dishes typically $60 \mathrm{~mm}$ in diameter (e.g. Corning Falcon \#353002);

- Sterile Petri dishes of larger diameter to preserve the cultural dishes from contamination;

- Sterile Pasteur glass pipettes with plugs;

- Sterile 2, 5, 10 and $25 \mathrm{ml}$ serological pipettes;

- Rubber or silicone bulbs for Pasteur and serological pipettes (can be sterilized with $70 \%$ ethanol);

- Water-resistant marker for labeling flasks and Petri dishes;

- Containers for disposal of aspirated medium and rubbish.

\section{Reagents:}

- Chloroform;

- $70 \%$ ethanol;

- Sterile standard cell culture medium: Minimum Medium (MEM) (e.g. Gibco ${ }^{\text {mix }}$ \#11095080) / Dulbecco's modified Eagle medium (DMEM) (e.g. BioloT \# 1.3.6) / Ham's F-12 medium (e.g. ThermoFisher Scientific \#11765054) containing $15 \%$ fetal bovine serum (FBS) (e.g. GE Healthcare HyClone ${ }^{\mathrm{Tx}}$ 
Fetal Bovine Serum \#SH30088.03), 2 mM L-gluta$\mathrm{min}$ (e.g. BioloT \#1.3.8.1) and antibiotics (200 U/ $\mathrm{ml}$ penicillin, $200 \mu \mathrm{g} / \mathrm{ml}$ streptomycin (e.g. BioloT \#1.3.18), $50 \mu \mathrm{g} / \mathrm{ml}$ gentamicin (e.g. BioloT \#1.3.17), $5 \mu \mathrm{g} / \mathrm{ml}$ amphotericin B (e.g. BioloT \#1.3.15)). FBS can be filtered through $0.45 \mu \mathrm{m}$ filter if necessary.

○ $\quad 0.25 \%$ and $0.05 \%$ Trypsin in $0.53 \mathrm{mM}$ EDTA (e.g. Paneco \#П034, \#П034п) for detaching adherent cells filtered through $0.45 \mu \mathrm{m}$ filter and stored at $-20^{\circ} \mathrm{C}$.

- Antibiotic incubation medium (ABT medium): standard cell culture medium with $1000 \mu \mathrm{g} / \mathrm{ml}$ streptomycin, $1000 \mathrm{U} / \mathrm{ml}$ penicillin (e.g. BioloT \#1.3.18), $25 \mu \mathrm{g} / \mathrm{ml}$ amphotericin B (e.g. BioloT $\# 1.3 .15$ ), and $250 \mu \mathrm{g} / \mathrm{ml}$ gentamicin (e.g. BioloT \#1.3.17);

- Sterile phosphate buffer (PBS): $137 \mathrm{mM} \mathrm{NaCl}$, $2.7 \mathrm{mM} \mathrm{KCl}, 10 \mathrm{mM} \mathrm{Na}_{2} \mathrm{HPO}_{4}, 1.8 \mathrm{mM} \mathrm{KH}_{2} \mathrm{PO}_{4}$, pH 7.4 (can be purchased e.g. ThermoFisher Scientific \#C10010500CP).

\section{Procedure:}

1. Prepare sterile working area: wash working surface with disinfectant and treat the working cabinet with UV irradiation. Just before use, switch on a laminar flow hood and allow it to reach working airflow pressure.

2. Prepare complete cell culture and antibiotic media. Warm cell culture medium, ABT medium and PBS to $28^{\circ} \mathrm{C}$ before use. Thaw and warm an aliquot of trypsin.

3. Put a red-eared slider in a desiccator with a small amount of chloroform for several minutes to euthanize it. It takes about $20 \mathrm{~min}$ to euthanize a red-eared slider aged 5-9 mos. (the shell is up to $7 \times 6 \mathrm{~cm}$ ).

4. Wash the turtle thoroughly in warm water with soap, treat skin folds carefully. Transfer the animal to the laminar flow hood. Sterilize the skin with $70 \%$ ethanol.

5. Dissect the animal with sterile scissors.

6. Dissect out the internal organs (heart, kidney, spleen) and pieces of connective tissue (e.g., mesentery) for procedure option A (see below). Put them in a sterile Petri dish with sterile $1 \times$ PBS solution. Use a separate Petri dish for each sample. We do not recommend using lung, intestine, and periorbital tissue samples as they might be strongly contaminated with bacteria and fungi. Liver does not contain many fibroblasts, and adult hepatocytes propagate poorly and undergo rapid deterioration.

7. Cut out small pieces of skin $\left(2-3 \mathrm{~mm}^{2}\right)$, put them into a sterile Petri dish containing ABT medium and incubate for $2 \mathrm{hrs}$ at room temperature.

Use the time of skin incubation in ABT solution to try an enzymatic method for cell culture establishment from internal tissues according to option A. If your task is establishment of cell cultures from only skin explants, follow option B.

\section{Option A. Establishment of primary cultures of red-eared slider cells by trypsinization of tissue samples (enzymatic method)}

A1. Transfer sample rinsed in $1 \times \mathrm{PBS}$ (step 6) to a new Petri dish, cut into small pieces with sterile scissors or a syringe.

A2. Add $0.8-1.5 \mathrm{ml}$ of $0.25 \%$ trypsin and pipette with a sterile Pasteur pipette. Aspirate tissue pieces and transfer them into a small sterile glass weighing bottle with a ground cover and a sterile stir bar inside, put the bottle onto a magnetic stirrer inside a carbon dioxide incubator at $28^{\circ} \mathrm{C}$ and mix for 10-15 mins, depending on the size of the pieces.

A3. Deactivate trypsin by adding $2-3 \mathrm{ml}$ cell culture medium.

A4. Transfer the cell suspension to a centrifuge tube, centrifuge at $1000 \mathrm{rpm}$ for 5 mins. Remove the supernatant.

A5. Resuspend the precipitate in the cell culture medium, then transfer the cells into a culture flask or culture dish (Fig. 2a). Tighten the flask cap (if using a flask with a gas-permeable lid; if not - leave the cap partly open to allow the incubator gas to enter the flask), label with the culture name, passage number and date.

A6. Put the flask (or dish) in an incubator at $28^{\circ} \mathrm{C}, 5 \%$ $\mathrm{CO}_{2}$.

A7. Regularly check flasks, noting turbidity and medium colour. Examine the culture under an inverted phase-contrast microscope, noting cell morphology (Fig. 2b) and viability, signs of contamination such as dead floating cells, presence of bacterial and/or fungal cells. If necessary, change culture medium. The time of stable primary cell culture establishment depends on the initial density of the cells attached to the surface of the culture flask.

A8. When the cells reach a confluent state (Fig. 2c), they have to be passed. Rinse them twice with $1 \times \mathrm{PBS}$, add $\sim 1 \mathrm{ml}$ of $0.25 \%$ trypsin and constantly observe them under the inverted phase microscope. When the cells become round, pipette gently to detach the cells and deactivate trypsin with 1.5-2 ml complete cell culture medium. Transfer cells in a centrifuge tube and centrifuge at $1000 \mathrm{rpm}$ for 5 mins. Remove the supernatant. Resuspend the precipitate in cell culture medium and transfer to a new flask of the same size (reseed the cells to a new flask at a dilution not more than 1:1). After 5-7 days, the cells 

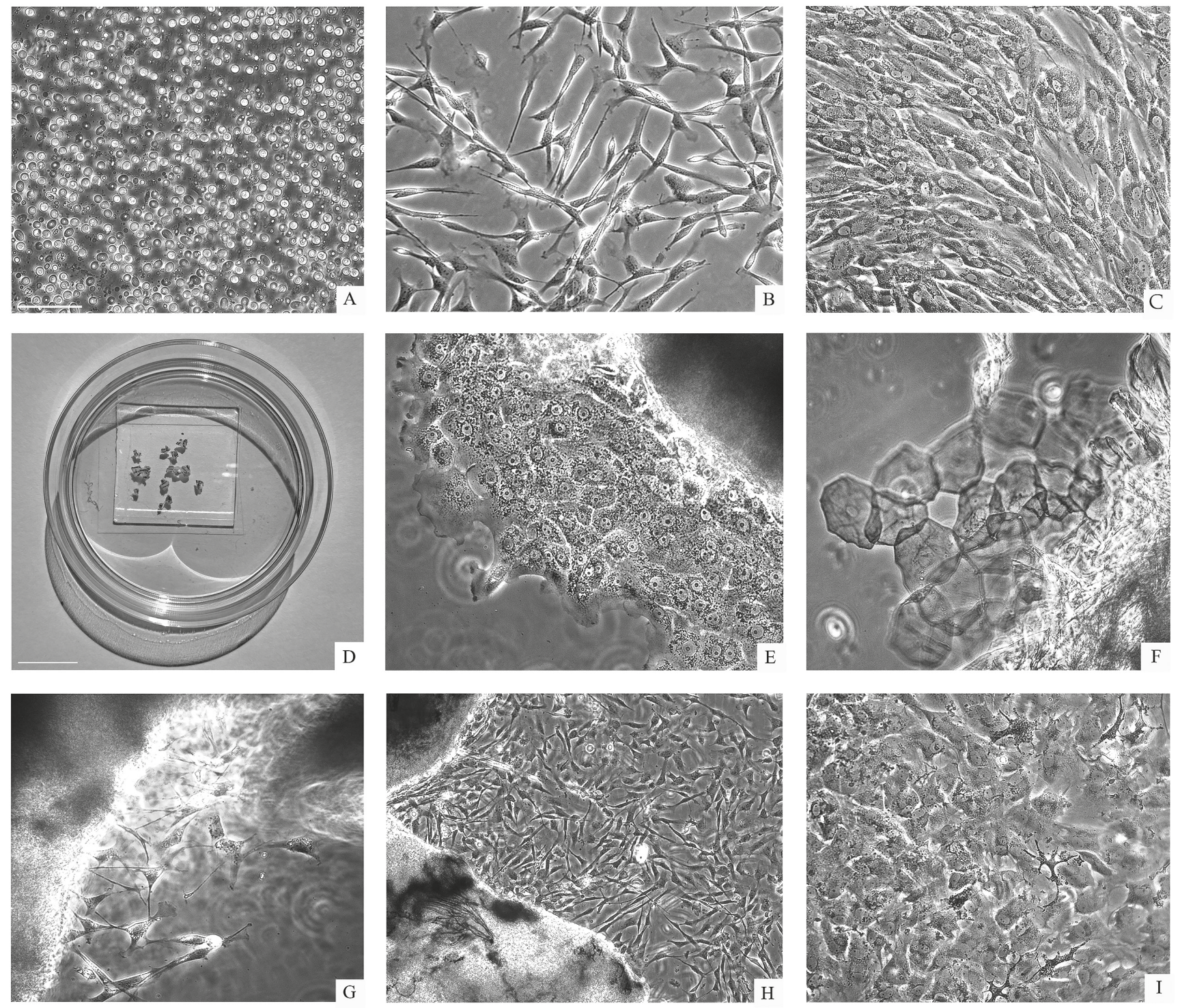

Fig. 2. Representative phase contrast photomicrographs of red-eared slider cells. (A) Cell suspension just after enzymatic digestion of mesentery pieces; (B) fibroblast-like cells derived from mesentery; (C) fibroblast-like cells reached $80 \%$ confluence; (D) view of freshly isolated skin fragments pressed down by a slide piece in a Petri dish with cell culture medium; (E) morphology of primary cultured keratinocyte-like cells on day 5 after initial cultivation of skin explants; (F) terminally differentiated keratinocyte-like cells on day 9; (G) during days 5-14, the first fibroblast-like cells appear around the explant; $(\mathrm{H})$ numerous fibroblast-like cells appear on day 14, when the explant was reused for inoculating new cells; (I) morphology of fibroblast-like and melanocyte-like cells on day 26 of skin explant cultivation. Images A-C, E-I are at the same magnification, scale bar $-50 \mu \mathrm{m}$; scale bar for image $\mathrm{D}-10 \mathrm{~mm}$.

form a monolayer. Now it is possible to reseed the cells at a dilution of 1:2. Label the flask, indicating the culture name, passage number and date.

\section{Option B. Establishment of cell cultures from skin explants}

B1. After incubation in ABT solution (step 7), transfer the skin fragment into a new Petri dish with a drop of cell culture medium (keep skin wet).

B2. Cut up the skin fragment into tiny pieces, holding sterile scalpel blades with sterile forceps at $45^{\circ}$. Ster- ile histological needles can also be used for this action.

B3. Inoculate 12-14 tiny pieces into a drop of cell culture medium in a new Petri dish, close them with a sterile slide piece measuring $5 \times 5 \mathrm{~mm}$.

B4. Add the cell culture medium in the Petri dish so that the bottom is completely covered $(\sim 4 \mathrm{ml}$ of culture medium for a Petri dish of $6 \mathrm{~cm}$ in diameter) (Fig. 2d).

B5. Label with sample name and date.

B6. Put the dish in the carbon dioxide incubator $\left(28^{\circ} \mathrm{C}\right.$, $5 \% \mathrm{CO} 2)$. 
B7. During the next days, regularly check for medium opacity and colour in the Petri dish, examine skin piece viability under an inverted phase-contrast microscope. As a rule, epithelial-like cells are the first to emerge from the skin fragment (Fig. 2e, f), and they dominant for approximately 2 wks. As they go through passages, the fibroblast-like cells become more proliferative and for about $1 \mathrm{mo}$. they form the dominant population in the culture (Fig. 2g, i).

B8. During cell growth, phenol red added to standard cell-culture medium changes color from bright red ( $\mathrm{pH}$ 7.4) to yellow (low $\mathrm{pH}$ ) or purple (high $\mathrm{pH}$ ) due to cell metabolites, indicating that the medium has changed. To change the medium, remove old culture medium with a sterile Pasteur pipette, lift the slide with a sterile histological needle, and add a new aliquot of cell culture medium. It is possible to transfer the skin pieces into a new $6 \mathrm{~cm}$ Petri dish, cover them again with a new sterile slide piece, and repeat steps B4-B6 so that new cells suitable for cultivation emerge (Fig. 2h). In this case fibroblast-like cells appear faster, for there is no need to adapt to the culture medium.

B9. To passage fibroblast-like cells, rinse the Petri dish twice with $1 \times \mathrm{PBS}$, add $\sim 0.8 \mathrm{ml}$ of $0.05 \%$ trypsin (into a $6 \mathrm{~cm}$ dish) and follow step A8.

After 5-7 passages and performing the necessary tasks (for example, obtaining cytological and/or chromosome preparations), it is recommended to freeze cells for long storage according to standard procedure, using medium for cryopreservation (95\% fetal bovine serum, $5 \%$ dimethyl sulfoxide).

\section{Conclusion}

Here, we report the establishment of red-eared slider cell lines using enzymatic and migration methods. Both protocols were effective; the most important thing to bear in mind when sampling a tissue and establishing primary cultures is to process with antibiotics and antimycotics as thoroughly as possible, using concentrations several times higher than those for cultivating mammalian cells. We could suggest that dermal-tissue samples from the tail tip can be taken directly from a live animal, but in this case the incubation time in the ABT medium can be increased. However, careful preparation of the euthanized animal and internal organ biopsy significantly reduces the risk of contamination by microorganisms. When internal organ samples are used, protocol A is better. The cultivated cells are of various morphology resembling keratinocytes, fibroblasts, and melanocytes (Fig. 2). When established, from a confluent flask with fibroblast-like cells it is possible to obtain nearly 5 million cells. After a month of cultivation (3-4 passages), fibroblast-like cells can gather to form dense conglomerates similar to "embryoid bodies". Cultivated red-eared slider cells are remarkable for their viability, unlike, for example, primary cell cultures of different species of birds and mammals. Slider cells forgive minor errors in the protocol and therefore can be used for student training. The present protocol can serve as the basis for further studies on features and behavior of turtle cells in culture.

\section{Acknowledgements}

The authors are grateful to Nadezhda Pleskach (Institute of Cytology of the Russian Academy of Sciences, Saint Petersburg, Russia) and Valerie Fillon (National Institute of Agronomical Research, Toulouse, France) for their helpful advice; to Anton Radaev (Chromas Core Facility of Saint Petersburg State University, Saint Petersburg, Russia) for technical support. All manipulations were performed using the equipment of Chromas Core Facility of Saint Petersburg State University Research Park.

\section{References}

Bansal, S., Biggar, K. K., Krivoruchko, A., and Storey, K. B. 2016. Response of the JAK-STAT signaling pathway to oxygen deprivation in the red eared slider turtle, Trachemys scripta elegans. Gene 593(1):34-40. https://doi. org/10.1016/j.gene.2016.08.010

Christiansen, J., Johnson, J., Henderson, E. R., Budke, B., and Lynch, M. 2001. The relationship between telomeres, telomerase, reptilian lifespan, and reptilian tissue regeneration. Proceedings of the lowa Space Grant Consortium $1-10$.

Czerwinski, M., Natarajan, A., Barske, L., Looger, L. L., and Capel, B. 2016. A timecourse analysis of systemic and gonadal effects of temperature on sexual development of the red-eared slider turtle Trachemys scripta elegans. Developmental Biology 420(1):166-177. https://doi. org/10.1016/j.ydbio.2016.09.018

Fukuda, T., Eitsuka, T., Donai, K., Kurita, M., Saito, T., Okamoto, H., Kinoshita, K., Katayama, M., Nitto, H., Uchida, T., Onuma, M., Sone, H., Inoue-Murayama, M., and Kiyono, T. 2018. Expression of human mutant cyclin dependent kinase 4, Cyclin D and telomerase extends the life span but does not immortalize fibroblasts derived from loggerhead sea turtle (Caretta caretta). Scientific Reports 8(1):9229. https://doi.org/10.1038/s41598-018-27271-x

Fukuda, T., Katayama, M., Kinoshita, K., Kasugai, T., Okamoto, H., Kobayashi, K., Kurita, M., Soichi, M., Donai, K., Uchida, T., Onuma, M., Sone, H., Isogai, E., and InoueMurayama, M. 2014. Primary fibroblast cultures and karyotype analysis for the olive ridley sea turtle (Lepidochelys olivacea). In Vitro Cellular and Developmental Biology - Animal 50(5):381-383. https://doi.org/10.1007/ s11626-013-9715-0

Fukuda, T., Kurita, J., Saito, T., Yuasa, K., Kurita, M., Donai, K., Nitto, H., Soichi, M., Nishimori, K., Uchida, T., Isogai, E., Onuma, M., Sone, H., Oseko, N., and Inoue-Murayama, M. 2012. Efficient establishment of primary fibroblast cultures from the hawksbill sea turtle (Eretmochelys imbricata). In Vitro Cellular and Developmental Biology Animal 48(10):660-665. https://doi.org/10.1007/s11626012-9565-1

Goldstein, S. 1974. Growth of cultured cells from the Galapagos tortoise. Experimental Cell Research 83:279-302. https://doi.org/10.1016/0014-4827(74)90342-5 
Gomes, N. M., Shay, J.W., and Wright, W. E. 2010. Telomere biology in Metazoa. FEBS Letters 584(17):3741-3751. https://doi.org/10.1016/j.febslet.2010.07.031

Guo, H., Xia, Z., Tang, W., Mao, Z., Qian, G., and Wang, C. 2016. Establishment and characterization of a cell line from the Chinese soft-shelled turtle Pelodiscus sinensis. In Vitro Cellular and Developmental Biology - Animal 52(6):673682. https://doi.org/10.1007/s11626-016-0015-3

Hong, M., Jiang, A., Li, N., Li, W., Shi, H., Storey, K. B., and Ding, L. 2019. Comparative analysis of the liver transcriptome in the red-eared slider Trachemys scripta elegans under chronic salinity stress. PeerJ 21(7):e6538. https://doi.org/10.7717/peerj.6538

Lu, Y., Nerurkar, V. R., Aguirre, A. A., Work, T. M., Balazs, G. H., and Yanagihara, R. 1999. Establishment and characterization of 13 cell lines from a green turtle (Chelonia mydas) with fibropapillomas. In Vitro Cellular and Developmental Biology - Animal 35(7):389-393. https://doi. org/10.1007/s11626-999-0113-6

Mahlin, M. D. 1997. Turtles in your home. 96 pp. Izdatelstvo Zoomarket, Moscow. (In Russian)

Mansell, J. L., Jacobson, E. R., and Gaskin, J. M. 1989. Initiation and ultrastructure of a reptilian fibroblast cell line obtained from cutaneous fibropapillomas of the green turtle, Chelonia mydas. In Vitro Cellular and Developmental Biology 25(11):1062-1064. https://doi.org/10.1007/ BF02624142
Paitz, R. T., Haussmann, M. F., Bowden, R. M., Janzen, F. J., and Vleck, C. M. 2005. Long telomeres may minimize the effect of aging in the Painted Turtle. Integrative and Comparative Biology 44(6):617.

Ramsey, M. and Crews, D. 2007. Steroid signaling and temperature-dependent sex determination-Reviewing the evidence for early action of estrogen during ovarian determination in turtles. Seminars in Cell and Developmental Biology 20(3):283-92. https://doi.org/10.1016/j. semcdb.2008.10.004

Ramsey, M. and Crews, D. 2009. Steroid signaling system responds differently to temperature and hormone manipulation in the red-eared slider turtle (Trachemys scripta elegans), a reptile with temperature-dependent sex determination. Sex Development 1(3):181-196. https://doi. org/10.1007/000102107

Webb, S. J., Zychowski, G. V., Bauman, S. W., Higgins, B. M., Raudsepp, T., Gollahon, L. S., Wooten, K. J., Cole, J. M., and Godard-Codding, C. 2014. Establishment, characterization, and toxicological application of loggerhead sea turtle (Caretta caretta) primary skin fibroblast cell cultures. Environmental Science and Technology 48(24):1472814737. https://doi.org/10.1021/es504182e

Xu, H., Zhu, X., Li, W., Tang, Z., Zhao, Y., and Wu, X. 2018. Isolation and in vitro culture of ovarian stem cells in Chinese softshell turtle (Pelodiscus sinensis). Journal of Cellular Biochemistry 119(9):7667-7677. https://doi.org/10.1002/jcb.27114 